\title{
Visualization of the Process of Processing Welds by a Deformation Wave*
}

\author{
Andrey Kirichek ${ }^{1[0000-0002-3823-0501]}$, Sergey Barinov² and \\ Alexandr Yashin ${ }^{3[0000-0002-3186-1300]}$ \\ ${ }^{1}$ Bryansk State Technical University, 50 let Octyabrya Blvd. 7, 241035 Bryansk, Russia \\ avk57@yandex.ru \\ ${ }^{2}$ Murom Institute (branch) of Vladimir State University, Orlovskaya Str. 23, 602264 Murom, \\ Russia \\ box64 erambler.ru \\ ${ }^{3}$ Murom Institute (branch) of Vladimir State University, Orlovskaya Str. 23, 602264 Murom, \\ Russia \\ yashin2102@yandex.ru
}

\begin{abstract}
The aim of the paper is to obtain a unified finite element model of a complex process, which makes it possible to obtain visual information related to the influence of the welding process parameters on the results of the process of wave strain hardening of the weld material. Modeling of sequentially executed technological processes of different physical nature - welding and hardening, makes it possible to obtain more general and objective visual information about the process as a whole. Modeling in the Ansys software package is performed in stages, with the output of an earlier stage of modeling acting as the input data of the subsequent stage. At the first stage, the problem of visualizing the process of forming a weld is solved with the possibility of calculating temperature fields, stress and strain fields during heating and cooling of the welded workpiece. At the second stage, the calculated data is imported into the finite element model of processing welds with a deformation wave. A finite element model makes it possible to build microhardness maps for selected (dangerous) sections and visually monitor the change in stresses and strains in welded workpieces, depending on the technological modes of hardening by a deformation wave. The obtained visual information allows for a qualitative and quantitative assessment of the result of a complex process, which contributes to an increase in the bearing capacity and performance of the product as a whole.
\end{abstract}

Keywords: Finite element model, Visualization, Welding, Wave strain hardening, Temperature fields, Stress and strain fields.

Copyright (C) 2020 for this paper by its authors. Use permitted under Creative Commons License Attribution 4.0 International (CC BY 4.0).

* The reported study was funded by RFBR according to the research project No. 1838-20066. 


\section{Introduction}

In the modern world, digital technologies are considered as a means of describing the complete life cycle of a product - from design and manufacture to operation and disposal. Science-intensive industries have been given a daunting task even before the product and its constituent parts are put into production, to create, manufacture and test mathematical models under operating conditions. The least developed from the point of view of modeling are the technological processes of manufacturing parts. The problems of their modeling are largely associated not only with a large number of technological factors, but also with a change in the shape and size of a part during processing, a continuously and dynamically changing stress-strain state of a product, and the need to take into account thermal processes. The solution to the problem of transferring information about the product during the transition from one operation to another is also quite difficult. Since various software tools have been developed and proposed to simulate different operations, the loss of some information is inevitable at the stage of inter operational transition. The problem is especially acute for the transfer of information between technological processes that differ in the physical nature of the effects on the material of the original workpiece.

The aim of the paper is to obtain a unified finite element model of a complex process, which makes it possible to obtain visual information related to the influence of the welding process parameters on the results of the wave strain hardening (WSH) process of the weld material. Modeling of interconnected sequentially executed technological processes of different physical nature - welding and hardening, makes it possible to obtain more general and objective visual information about the process as a whole. The known finite element models of the welding process do not imply the modeling of subsequent effects on the weld [1-3]. The well-known means of modern engineering analysis in most cases do not specialize in modeling fast shock processes (lasting $10^{-7} \ldots 10^{-5}$ seconds), which is typical for WSH.

The essence of WSH [4] is wave loading of the processed material by shock pulses with a given duty cycle, energy and duration. WSH has the ability to increase microhardness and form compressive residual stresses at a depth of more than $10 \mathrm{~mm}$. This makes the use of the method promising for increasing the strength of welds. A finite element model of a shock system with an intermediate link (waveguide), tested on solid material, is known. It makes it possible to study the regularities of the influence of the parameters of the shock system elements and the material of the loading medium on the efficiency of the shock pulse energy transfer $[5,6]$, but does not allow using the results of modeling the welding process as initial information.

Modeling in the Ansys software package is performed in stages, with the output of an earlier stage of modeling acting as the input data of the subsequent stage. The choice of Ansys is based on the high reliability of the data obtained and a wide range of multidisciplinary calculation modules, combined on one platform. The use of a single platform greatly facilitates data exchange when solving multidisciplinary problems without loss of accuracy in calculations. In a complex formulation in relation to the indicated processes, the problem is solved for the first time. 


\section{Visualization of the process of processing welds by a deformation wave}

The development of a finite element model of the process of processing welds by a deformation wave consisted of two stages.

At the first stage, using the previously obtained data, a finite element model of the weld was created. For this, in the "Transient Thermal" module, in the "Geometry" section, the geometry of the welded specimen was created, and the weld was divided into face and root elements (Fig. 1). In the "Engineering Data" section, the properties of the processed material such as: yield stress, strength, density, thermal expansion coefficient, Young's modulus, Punson's coefficient, thermal conductivity, specific heat, tangential modulus, etc., were set. Some physical and mechanical properties were determined depending on the temperature. Further, a finite element mesh was formed in the welded workpiece. To solve thermal problems, the mesh was assigned the "Explicit" type. The elements of the weld were heated using the heat flow set by the "Heat Flow" function. The procedure for determining the value of the required heat flux during welding is presented in various sources, for example [7]. A heat flux value was assigned to each element of the weld. For the front and root welds, the heat flux values are different, this is due to the specifics of welding material with a thickness of more than $10 \mathrm{~mm}$. Then, the boundary value of convection "Convection" was assigned to all surfaces of the welded workpiece. It created the condition for all surfaces of the welded workpiece to come into contact with "standing" air. The task setup was completed by setting the calculation parameters - "Analysis Setting", in which the number of calculation steps was set. In the problem, each element of the weld was heated in one calculation step, and in addition to the calculation, two more steps were added. They recorded the process of stopping heating, and set the time during which the workpiece cools after welding. The result of the calculation in the Transient Thermal module was to obtain the temperature fields of the welded workpiece heating and cooling, which were then transferred to the "Static Structural" module to obtain thermal deformations that occur in the product after welding.

The geometry of the welded product and the material model were transferred to the "Static Structural" module from the "Transient Thermal" module (Fig. 1). The finite element mesh was re-formed. The "Fixed Support" boundary condition was assigned to the ends of the welded workpiece. It secures the edges of the workpiece in space. The boundary condition "Frictionless Support" was applied to the bottom of the welded workpiece to ensure its normal restraint, with freedom in the tangential direction. The "Imported Load" function was used to import temperature fields from the "Transient Thermal" module. The adjustment of the calculation parameters "Analysis Setting" was carried out in the same way as in the "Transient Thermal"module, which is necessary for adequate transmission and use in the calculation of temperature fields in time. After solving the problem in the "Static Structural" module, it became possible to assess the stresses and strains that occur in the workpiece after welding.

The second stage was the combination of the data obtained as a result of modeling a weld with a strain wave hardening model into a single finite element model of the process of processing welds with a strain wave. For this, the "Transient Structural" 
module was used. Import from the previous calculations of the values of stresses and strains, the geometry of the workpiece changed as a result of welding, was carried out using the "External Data" and "Mechanical Model" modules, respectively (Fig. 1).

In the "Transient Structural" module (Fig. 1), to the previously created geometry of the weld, one more body is added - a rod roller, through which the impact energy is communicated to the processed surface of the welded workpiece. Preparation for the calculation of the "Transient Structural" module began with setting the contact in the "Connectoins" section, in which the contact type was defined as "Frictional" and the friction coefficient value was set. To simplify the organization of contact settings between bodies, the "Contact Tool" function was created and enabled. The direct transfer of weld stresses to the "Transient Structural" module was performed using the "Imported Initial Stress" function. Restriction of the roller movement along one of the axes was set by the introduction of the Displacement boundary condition. Fastening of the edges of the welded workpiece in space was ensured by the "Frictionless Support" boundary condition, which was applied to the ends of the workpiece. The movement of the workpiece in the process of wave strain hardening was carried out using the "Velocity" function, which provided the setting of the kinematic speed of the workpiece movement in the selected direction.

The law of deformation of the welded workpiece by the roller was set using the "Force" function, which reflected the change in the impact force over time. The type of dependence was determined from previously solved contact problems based on the finite element model of a shock system with an intermediate link [2,3]. As a result, a shock impulse was modeled, the shape of which was described by the dependence of the impact force on time. The resulting shock impulse had decay and rise fronts, and, depending on the shock system parameters, could have a tail section providing a higher efficiency of the impact process. Thus, using the previously developed model of the impact system with an intermediate link, based on the specified parameters of the impact system and the properties of the processed material, the law of force variation for one impact in time was determined. The resulting dependence was used later in the "Transient Structural" module for a given number of strokes.

Setting up the "Analysis Setting" calculation parameters was reduced to turning on the "Auto Time Stepping" function and choosing the principle of calculating steps after a specified time, indicating the minimum and maximum time for calculating one step. After solving the problem, in the "Transient Structural" module it becomes possible to assess stresses, deformations, displacements, temperatures, etc. If it is necessary to study any other parameters or their combinations, they are activated before starting the calculation in the "Analysis Setting" or written in the command line.

As an example of using the developed technique, a unified finite element model of processing welds with a deformation wave was created. So the welded product consisted of two steel plates of 40X grade with dimensions of $150 * 70 * 10 \mathrm{~mm}$ (Fig. 2). Welding was carried out in two passes, semi-automatic, with the current strength of the root and face seam, respectively, 185 and 130A. The deposited material is steel $40 \mathrm{X}$ grade. Cutting the edges of welded workpieces was done in accordance with GOST 5264-80. WSH modes are: impact energy $70 \mathrm{~J}$; overlap coefficient $\mathrm{K}=0.3$; rod roller tool $40 \mathrm{~mm}$ long and $10 \mathrm{~mm}$ in diameter. 


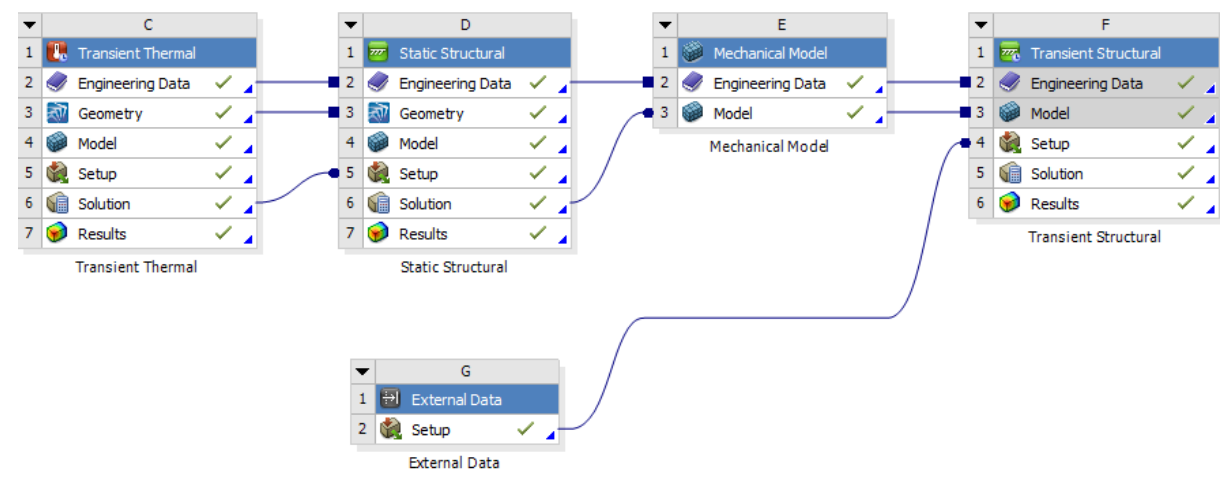

Fig. 1. Modular diagram of the model

As an example, seven impacts of the tool on the surface of the welded workpiece were modeled. The adequacy of the data obtained as a result of modeling was established on the basis of its comparison with experimental data obtained under similar conditions. In the model of the welded workpiece, the microhardness distribution map in the surface layer before and after the WSH was compared, the sizes of individual indentations and the distribution of the hardness map under them were estimated. The values obtained as a result of modeling correspond to the results of the experiment with a confidence level of 0.95 .

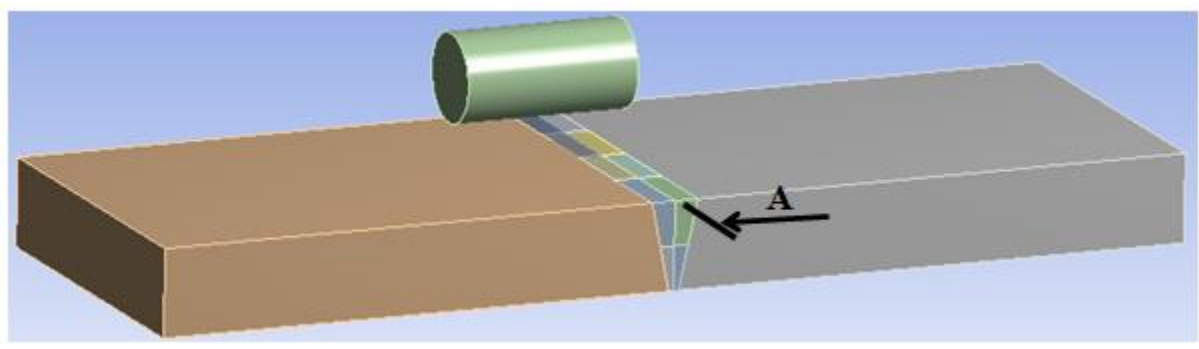

Fig. 2. Schematic model

Figures 3 and 4 show the distribution of residual stresses in welds before and after WSH. The data obtained indicate a decrease in the magnitudes of tensile stresses (data with a plus sign) and their transition to compressive stresses (data with a minus sign), on average, in depth by $8 \mathrm{~mm}$.

Summing up the work done, it should be noted that:

- at the first stage, the problem of visualizing the process offorming a weld with the possibility of calculating temperature fields, stress and strain fields during heating and cooling of the welded workpiece is solved;

- at the second stage, the calculated data are imported into the finite element model of processing welds with a deformation wave;

- a unified finite element model makes it possible to build microhardness maps for selected (dangerous) sections and visually track the change in stresses and strains in 
welded workpieces, depending on the technological modes of hardening by a deformation wave.

The obtained visual information allows for a qualitative and quantitative assessment of the result of a complex process, which contributes to an increase in the bearing capacity and performance of the product as a whole.

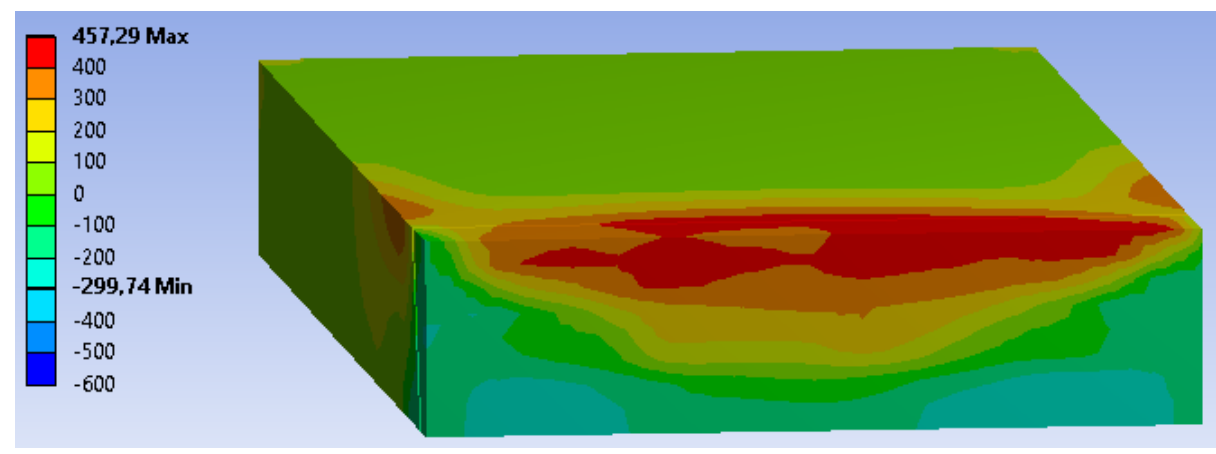

Fig. 3. Distribution of residual stresses in the sample after welding

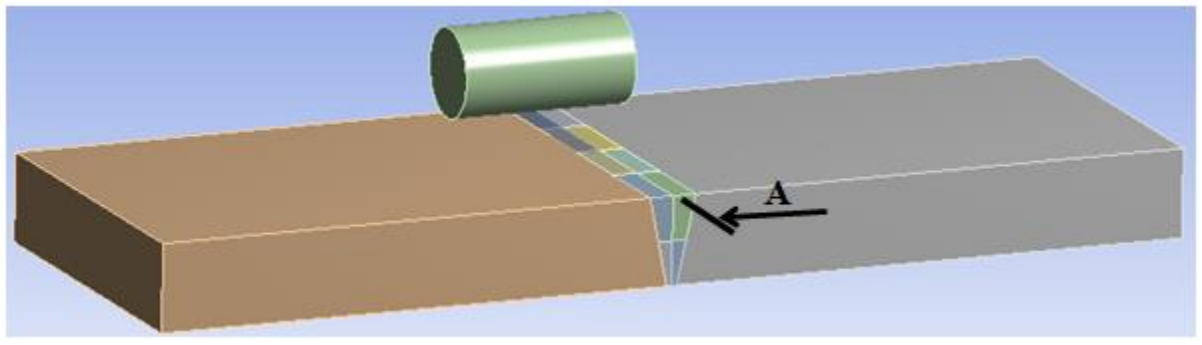

Fig. 4. Distribution of residual stresses in the welded specimen after WSH

\section{Acknowledgments}

The reported study was funded by RFBR according to the research project No. 18-3820066.

\section{References}

1. Pronin, A.: Development of methods for assessing the performance of circular welds of gas pipelines of compressor stations: dissertation ... Candidate of technical sciences: 25.00.19., Ukhta (2009).

2. Porowski, J., O'Donnell, W., et al.: Use of the mechanical stress improvement process to mitigate stress corrosion cracking in BWR piping system. Nuclear Engineering and Design 124, 91-100 (1990). 
Visualization of the Process of Processing Welds by a Deformation Wave 7

3. Bilenko, G., Morgunov E., Korobov Yu.: Computer modeling of the stress state of a welded joint made of stainless steel 03X18H9M3, performed by multi-pass orbital welding. Welding and diagnostics: collection of reports of the international forum, p. 35 (2015).

4. Kirichek, A., Soloviev, D., Lazutkin, A.: Technology and equipment for static-impulse processing by surface plastic deformation. M.: Mechanical engineering (2004).

5. Kirichek, A., Barinov, S., Ryzhkova, M., Yashin, A.: Visualizing the process of forming a shock pulse in the deformation zone. CEUR Workshop Proceedings 2485, pp. 265-267 (2019).

6. Kirichek, A., Barinov, S., Yashin, A., Konstantinov, A.: Study of the influence of cross section sizes of the rod shock system on the efficiency of shock pulse energy transfer to the deformation center. Applied Mathematics, Computational Science and Mechanics: Current Problems IOP Conf. Series: Journal of Physics: Conf. Series 1479, 012067 (2020).

7. Vasiliev K., Vill V., Volchenko V., and others: Welding in mechanical engineering: Handbook in 4 volumes. Mechanical Engineering, Moscow (1978-1979). 